Universidade Tecnológica Federal do Paraná - UTFPR

Campus Ponta Grossa - Paraná - Brasil

ISSN: 1981-3686/ v. 08, n. 02: p. 1348-1359, 2014

D.O.I. $10.3895 / \mathrm{S} 1981-36862014000200005$
Revista Brasileira de Tecnologia

Agroindustrial

\title{
QUALIDADE MICROBIOLÓGICA DO LEITE CRU EM FUNÇÃO DE MEDIDAS PROFILÁTICAS NO MANEJO DE PRODUÇÃO
}

\section{MICROBIOLOGICAL QUALITY OF RAW MILK IN FUNCTION OF THE PROPHYLACTIC MEASURES IN THE PRODUCTION HANDLING}

\author{
Eduardo da Silva Martins ${ }^{1}$; Nadabya Elizabeth Ventura Reis ${ }^{2}$ \\ ${ }^{1}$ Universidade do Estado de Minas Gerais - UEMG - Frutal - Brasil edusmartins@ yahoo.com.br \\ ${ }^{2}$ Universidade do Estado de Minas Gerais - UEMG - Frutal - Brasil nadabya@ hotmail.com
}

\begin{abstract}
Resumo
O presente trabalho teve por objetivo avaliar a qualidade microbiológica de leite cru produzido em quatro propriedades rurais de Frutal/MG, antes e após a adoção de medidas profiláticas na sua obtenção. Foi determinada a presença de bactérias mesófilas, psicrotróficas, coliformes totais e termotolerantes. Para a quantificação de bactérias mesófilas e psicrotróficas, foi feita contagem padrão em placas com incubação a $35^{\circ} \mathrm{C}$ durante $48 \mathrm{~h}$. e a $7{ }^{\circ} \mathrm{C}$ durante 10 dias, respectivamente. Para determinação de coliformes totais, as amostras foram inoculadas em Caldo Verde Brilhante Bile $2 \%$, e incubadas a $35{ }^{\circ} \mathrm{C}$ por até $48 \mathrm{~h}$, e para coliformes termotolerantes foram inoculadas em meio EC, e incubadas a $45{ }^{\circ} \mathrm{C}$, pelo mesmo período. Verificou-se que na propriedade 1 houve diminuição de bactérias mesófilas em $75 \%$ das coletas. Na propriedade 2 isso ocorreu em $50 \%$ das amostras. Nestas propriedades, em $25 \%$ das coletas o resultado foi superior ao limite estabelecido pela legislação, após as medidas profiláticas. Nas propriedades 3 e 4 não foi detectada presença acima do permitido. Para psicrotróficas, houve contagem elevada apenas na $2^{a}$ coleta da propriedade 4, antes da sugestão das medidas profiláticas. Para os coliformes totais, antes das medidas sugeridas as propriedades 1, 2 e 3 apresentavam elevado índice de contaminação em todas as coletas, enquanto que na propriedade 4 houve sua presença em apenas uma. Após as medidas profiláticas, observou-se que a contaminação por este grupo diminuiu, com exceção da propriedade 1. Para coliformes termotolerantes, nas propriedades 1 e 2 houve redução da contaminação após as medidas, enquanto que nas propriedades 3 manteve-se o índice de $25 \%$. Na propriedade 4 não foi detectada sua presença em nenhuma amostra. Concluiu-se que após a adoção das medidas profiláticas houve uma melhoria na maioria dos indicadores microbiológicos das amostras de leite avaliadas.
\end{abstract}

Palavras-chave: qualidade microbiológica; leite cru; propriedades rurais. 


\section{Introdução}

O município de Frutal, localizado no Triângulo Mineiro, está numa das principais regiões leiteiras do Estado de Minas Gerais, por possuir significativa produção e indústrias que recebem e processam o leite, comercializando-o tanto na forma fluida como em produtos derivados.

O leite, por ser um alimento rico em nutrientes contendo proteínas, carboidratos, gorduras, vitaminas e sais minerais, é facilmente contaminado por diferentes grupos de micro-organismos, sendo que a presença de bactérias patogênicas no leite cru é uma preocupação de saúde pública, pelo risco potencial para quem o consome diretamente ou na forma de seus derivados, e até para quem o manuseia. O leite cru contaminado pode ser ainda, fonte de contaminação cruzada para os produtos lácteos processados, pela contaminação do ambiente na indústria (ARCURI et al., 2006).

Depois de secretado no do úbere, o leite pode ser contaminado a partir de três principais fontes: de dentro da glândula mamária, da superfície exterior do úbere e tetos, e da superfície do equipamento e utensílios de ordenha e tanque (SANTOS e FONSECA, 2001).

Desta forma, a saúde da glândula mamária, a higiene de ordenha, o ambiente em que a vaca fica alojada e os procedimentos de limpeza do equipamento de ordenha são fatores que afetam diretamente a contaminação microbiana do leite cru (GUERREIRO et al., 2005). Além disso, o controle da temperatura e do período de tempo de armazenamento do leite é fundamental, uma vez que estes dois fatores estão diretamente ligados com a multiplicação dos micro-organismos presentes no leite (FONSECA, 1998).

Alguns grupos de micro-organismos são utilizados como indicadores da qualidade dos alimentos, como o leite cru. A contagem em placas de bactérias mesófilas é comumente empregada para indicar a qualidade sanitária dos alimentos. Assim, mesmo que os patógenos estejam ausentes e que não tenham ocorrido alterações organolépticas no alimento, altas contagens deste grupo indica que o alimento é insalubre (FRANCO e LANDGRF, 2008).

A presença de bactérias psicrotróficas pode ocasionar problemas tecnológicos associados à atividade de enzimas proteolíticas e lipolíticas, sendo que muitas destas enzimas são termorresistentes e estão relacionadas às perdas de qualidade e à redução da vida de prateleira do leite UHT e de outros produtos lácteos (CHEN, DANIEL e COLBIER, 2003; PINTO, MARTINS e VANETTI, 2006).

Com relação aos coliformes, pode-se diferenciar dois grupos: os coliformes totais, utilizados para avaliar as condições higiênicas, limpeza e sanificação; e os coliformes termotolerantes, que são indicadores de contaminação fecal (SIQUEIRA, 1995).

A Instrução Normativa 62/2011 estabelece as condições de sanidade, higiene e nutrição animal, bem como da refrigeração do leite. Assim, a qualidade do leite cru que chega à indústria 
deve ser garantida pela ordenha, ou seja, a higiene de vacas sadias e bem alimentadas, seguida de imediata refrigeração do leite na propriedade rural e de seu transporte a granel em tanques isotérmicos até a indústria.

Este trabalho teve por objetivo avaliar a qualidade microbiológica do leite produzido em quatro propriedades rurais do município de Frutal-MG, em função adoção de medidas profiláticas durante sua obtenção, visando avaliar a qualidade do leite antes (como controle) e após as sugestões das medidas profiláticas.

\section{Material e Métodos}

\section{Escolha das propriedades e medidas profiláticas}

Para a escolha das propriedades, foi seguida metodologia relatada por Arcuri et al. (2006): inicialmente, foram realizadas visitas a algumas propriedades fornecedoras de leite de vaca, principalmente propriedades de pequeno porte, para observar as condições higiênicas durante e após o processo de ordenha.

As observações das características das propriedades foram coletadas por meio de um questionário, contendo itens como número de vacas, tipo de ordenha e número de ordenhas por dia, o qual foi respondido pelo responsável de cada uma delas.

Foram observadas quanto à presença ou ausência em cada propriedade, algumas das medidas profiláticas abaixo, tais como:

- Limpeza do local de ordenha e lavagem de utensílios e equipamentos: como é feita, quais produtos foram utilizados.

- Higienização dos animais: se é feito ou não a desinfecção dos tetos das vacas.

- Teste de mastite nos animais: se é feito ou não.

- Higiene dos ordenhadores/operadores: se é feita limpeza e desinfecção das mãos.

- Contenção da presença de outros animais no local e manejo dos animais: como é feito este controle.

- Higienização do tanque ou latão: como é feita.

- Resfriamento do leite: temperatura utilizada e tempo máximo de armazenamento.

- Qualidade da água da propriedade: se são feitas avaliações laboratoriais ou não.

A partir do conhecimento e da observação sobre o cumprimento ou não destas medidas, sugeriu-se as medidas profiláticas visando à melhoria da qualidade do leite nas propriedades avaliadas. 


\section{Coleta, preparação e transporte das amostras}

As amostras de leite de cru produzido em propriedades rurais de pequeno porte, localizadas no município de Frutal/MG, foram coletadas mensalmente, totalizando 4 amostragens usadas como controle (sem adoção de medidas profiláticas) e 4 após as sugestões de medidas profiláticas.

As amostras foram coletadas assepticamente em frascos esterilizados, sendo acondicionadas em caixa de material isotérmico, contendo cubos de gelo, e transportadas até o Laboratório de Microbiologia da Universidade do Estado de Minas Gerais (UEMG, campus de Frutal), onde foram analisadas. As mesmas ficaram mantidas em baixa temperatura até o momento das análises microbiológicas, as quais foram realizadas no máximo em 2 horas após a coleta.

O leite foi medido assepticamente e $25 \mathrm{~mL}$ de cada amostra foram adicionados a $225 \mathrm{~mL}$ de água peptonada $0,1 \%$ esterilizada, obtendo assim a diluição $10^{-1}$. Após homogeneização das amostras, foram preparadas as demais diluições decimais $\left(10^{-2}\right.$ e $\left.10^{-3}\right)$, pela transferência $1,0 \mathrm{~mL}$ da diluição $10^{-1}$ e $10^{-2}$, respectivamente, para tubos contendo $9,0 \mathrm{~mL}$ de água peptonada.

\section{Análises microbiológicas}

As análises microbiológicas foram feitas antes (como controle) e após a adoção de medidas para a melhoria da sua qualidade, visando estabelecer se houve uma efetiva melhoria na qualidade do leite após as sugestões de medidas.

\section{Contagem de bactérias mesófilas}

Para a quantificação de bactérias mesófilas, foi feita a contagem padrão em placas, com incubação a $35^{\circ} \mathrm{C} \pm 1{ }^{\circ} \mathrm{C}$, durante $48 \mathrm{~h}$. Para esta análise, foram transferidos $1,0 \mathrm{~mL}$ de cada diluição em uma placa de Petri, na qual foram adicionados 15,0 mL de Ágar Padrão para Contagem (PCA), fundido e resfriado em banho-maria a $45{ }^{\circ} \mathrm{C}$, sendo a amostra homogeneizada pela movimentação da placa em movimentos em forma de " 8 ". Após o período de incubação, foram contadas as colônias, nas placas que apresentaram crescimento de no mínimo 25 e no máximo 250 colônias.

\section{Contagem de bactérias psicrotróficas}

Para a quantificação de bactérias psicrotróficas, foi adotado o mesmo procedimento para a contagem de mesófilas, exceto que a temperatura de incubação que foi de $7{ }^{\circ} \mathrm{C}$, e as placas ficaram incubadas durante 10 dias. 


\section{Determinação de coliformes totais e termotolerantes}

Para determinação do Número Mais Provável (NMP) de coliformes totais, de cada diluição $\left(10^{-1} \mathrm{a} 10^{-3}\right)$, foram tomadas três porções de $1 \mathrm{~mL}$ cada e inoculadas, respectivamente, em três tubos contendo $9 \mathrm{~mL}$ de Caldo Lauril Sulfato Triptose contendo um tubo de Durham invertido, obtendose três séries de três tubos. Foi utilizado um tubo controle do meio de cultura e outro controle do meio de cultura e diluente, os quais foram incubados em estufa a $35-37{ }^{\circ} \mathrm{C}$, por $24-48$ horas. Os subcultivos positivos foram semeados em tubos contendo $9 \mathrm{~mL}$ de Caldo Verde Brilhante Bile $2 \%$ com tubo de Durham invertido, incubando-os a $35{ }^{\circ} \mathrm{C}$, durante 24 a 48 horas. A prova foi considerada positiva somente quando se verificava turvação do meio e produção de gás nos tubos de Durham, dentro de um período de incubação máximo de 48 horas. A determinação quantitativa foi realizada de acordo com a técnica do NMP, recomendada pela American Public Health Association (1992).

Uma alçada de cada cultura foi tomada dos tubos positivos de Caldo Verde Brilhante Bile $2 \%$ e transferida para tubos de Caldo E.C, contendo tubos de Durham invertidos, e incubados a 45,5 ${ }^{\circ} \mathrm{C}$, em banho-maria com agitação, para a determinação de coliformes termotolerantes. Após a incubação por 24 a 48 horas foi realizada a leitura, e os tubos que apresentavam turvação do meio e produção de gás foram considerados positivos para bactérias do grupo. Para cada diluição, o número de tubos positivos foi anotado e quantificado através da tabela de NMP, determinando, assim, o NMP de bactérias coliformes fecais por $\mathrm{mL}$ de leite cru.

\section{Resultados e Discussão}

\section{Características de cada propriedade}

As propriedades rurais avaliadas possuem as seguintes características:

- Propriedade 1: possui 18 vacas, sendo a sua ordenha mecânica. O estábulo não é cimentado. Seu tanque de refrigeração fica distante do curral aproximadamente 50 metros e antes das dicas de higiene profiláticas a limpeza era somente com detergente neutro. É feita apenas uma ordenha por dia. A higiene nos tetos das vacas era somente com um único pano não sendo trocado todos os dias e não era feita a higiene das mãos dos ordenadores.

- Propriedade 2: é de pequeno porte e possui somente duas vacas. A ordenha é manual. O estábulo não é cimentado é não possui tanque de refrigeração. O sistema aqui utilizado é o latão sem refrigeração. O leite fica aproximadamente 01h30min. até o leiteiro passar. Esse latão é lavado com detergente neutro e a quantidade de ordenhas por dia é somente uma vez também. A maneira 
que se higienizava os tetos da vaca era com água e secava com um pano e não havia procedimentos corretos de higiene das mãos do ordenhador.

- Propriedade 3: possui 8 vacas em lactação. Sua ordenha é manual. O estábulo não é cimentado. O leite é retirado e colocado em latões sem refrigeração. Esta fazenda não fornece esse leite para nenhum laticínio, sendo este leite utilizado para produzir queijos e a quantidade de ordenhas é uma vez ao dia. O leite era colocado, antes das sugestões de melhoria, em latões de tinta, e depois de ser retirado este já era direcionado para o recipiente de coagulação do leite para a obtenção do queijo. Após a sugestão das medidas, antes deste leite ser coagulado ele passou a ser fervido.

- Propriedade 4: é a de maior porte, dentre as analisadas. Possui 35 vacas em lactação. Sua ordenha é manual com 2 ordenhadores. O leite é retirado duas vezes por dia, na parte da manhã por volta das 08h30min. e a tarde por volta das 15:00 h. Possui tanque de refrigeração perto do estábulo. O estábulo é coberto, porém não é cimentado e a limpeza é realizada com detergente neutro e ácido, e a coleta do leite ocorre a cada 48h. Nesta fazenda, os ordenhadores tomam cuidados de acordo com as normas na higienização dos tetos, das mãos e dos utensílios.

\section{Qualidade microbiológica do leite nas propriedades avaliadas}

\section{Propriedade 1}

$\mathrm{Na}$ propriedade 1, para as bactérias mesófilas totais, houve melhoria nos índices de contaminação nas coletas 1, 3 e 4, após a adoção das medidas sugeridas, com redução mais expressiva na coleta 1 , na qual o valor passou de $1,2.10^{5}$ UFC.mL $L^{-1}$ para $6,9.10^{2}$ UFC.mL ${ }^{-1}$. A exceção foi a $2^{\mathrm{a}}$ coleta, na qual o índice aumentou, inclusive sendo o único acima do padrão permitido pela legislação vigente, que é de $6,0.10^{5}$ UFC.mL ${ }^{-1}$, de acordo com a Instrução Normativa 62/2011 (BRASIL, 2011) (Tabela 1).

Para os coliformes totais, altas contagens continuaram sendo observadas. Não há padrão pela legislação em relação ao limite de coliformes totais em leite cru refrigerado. A literatura dita apenas que contagens acima de $10^{2}$ UFC.mL ${ }^{-1}$ de micro-organismos do grupo coliforme indicam falhas na higiene durante e entre as ordenhas (CHAMBERS, 2002 apud SILVA et al., 2011). Assim, observou-se que nesta propriedade alguma(s) da(s) medida(s) profilática(s) sugerida(s) visando melhorias na higienização geral não foi(ram) seguida(s) com rigor, visto que altas contagens de coliformes totais continuaram ocorrendo. 
Por outro lado, para bactérias psicrotróficas e de coliformes termotolerantes, verificou-se que houve melhoria nos índices.

Com relação às psicrotróficas, nenhuma amostra coletada após as sugestões de melhorias apresentou este grupo, sendo que antes havia 3 amostras positivas. Apesar de não haver limite estabelecido pela legislação em leite cru refrigerado, sua presença é preocupante, já que algumas espécies podem alterar as características do leite, bem como serem prejudiciais à saúde dos consumidores. De acordo com Pinto et al. (2006), contagens de psicrotróficas a partir de 1,0 x $10^{5}$ UFC.mL $L^{-1}$ são suficientes para causar alterações em leites e derivados, resultado não observado em nenhuma das coletas realizadas nesta propriedade.

Para os coliformes termotolerantes, havia 3 coletas com contagens acima de $10^{2}$ NMP.mL ${ }^{-1}$ antes, enquanto que após as medidas houve 2 coletas acima deste valor (as $2^{\mathrm{a}}$ e $4^{\mathrm{a}}$ coletas) (Tabela 1). Mesmo com esta diminuição, os resultados demonstram quem há necessidade de maior rigor na melhoria das condições sanitárias durante a obtenção do leite nesta propriedade.

Tabela 1 - Determinação de bactérias mesófilas, psicrotróficas e coliformes totais e termotolerantes, nas amostras de leite cru provenientes da propriedade 1, antes e após as sugestões de medidas profiláticas.

\begin{tabular}{|c|c|c|c|c|}
\hline & \multicolumn{4}{|c|}{ Mesófilos (UFC.mL ${ }^{-1}$ ) } \\
\hline & Coleta 1 & Coleta 2 & Coleta 3 & Coleta 4 \\
\hline ANTES & $1,2.10^{5}$ & $5,0.10^{4}$ & $9,4.10^{4}$ & $3,1.10^{5}$ \\
\hline DEPOIS & $6,9.10^{2}$ & $1,8.10^{6}$ & $1,4.10^{4}$ & $1,6.10^{5}$ \\
\hline \multirow[t]{3}{*}{ Padrão (UFC/g) } & & $6,0.10^{5}$ & & \\
\hline & \multicolumn{4}{|c|}{ Psicrotróficos (UFC.mL $\left.{ }^{-1}\right)$} \\
\hline & Coleta 1 & Coleta 2 & Coleta 3 & Coleta 4 \\
\hline ANTES & 0 & $9,2.10^{2}$ & $7,5.10^{4}$ & $1,4.10^{3}$ \\
\hline DEPOIS & 0 & 0 & 0 & 0 \\
\hline \multirow[t]{3}{*}{ Padrão } & \multicolumn{4}{|c|}{ Não há } \\
\hline & \multicolumn{4}{|c|}{ Coliformes Totais (NMP.mL $L^{-1}$ ) } \\
\hline & Coleta 1 & Coleta 2 & Coleta 3 & Coleta 4 \\
\hline ANTES & $>1100$ & $>1100$ & $>1100$ & $>1100$ \\
\hline DEPOIS & $4,6.10^{3}$ & $>1100$ & $4,6.10^{3}$ & $>1100$ \\
\hline \multirow[t]{3}{*}{ Padrão } & \multicolumn{4}{|c|}{ Não há } \\
\hline & \multicolumn{4}{|c|}{ Coliformes Termotolerantes (NMP.mL ${ }^{-1}$ ) } \\
\hline & Coleta 1 & Coleta 2 & Coleta 3 & Coleta 4 \\
\hline ANTES & $1,1.10^{4}$ & $>1100$ & 0 & $>1100$ \\
\hline DEPOIS & $2,3.10$ & $1,5.10^{2}$ & $9,3.10$ & $>1100$ \\
\hline Padrão & & Não há & & \\
\hline
\end{tabular}

\section{Propriedade 2}

Na propriedade 2, houve melhorias nos índices de bactérias mesófilas totais após a adoção de medidas profiláticas em 2 coletas $\left(1^{\mathrm{a}}\right.$ e $\left.3^{\mathrm{a}}\right)$. Na coleta 4 , houve um pequeno aumento e na coleta 2 houve um aumento mais significativo, inclusive com índice acima do permitido (Tabela 2). 
Já para bactérias psicrotróficas, houve melhoria, uma vez que uma amostra estava contaminada por este grupo antes e nenhuma após as medidas sugeridas (Tabela 2).

Para os coliformes totais e termotolerantes, verificou-se que houve melhoria nos índices. Com relação aos coliformes totais, nenhuma amostra coletada após as sugestões de melhorias apresentou este grupo, sendo que antes havia 4 amostras positivas, com elevadas contagens.

Para os coliformes termotolerantes, havia 2 amostras com contagem para o grupo, inclusive uma acima de $1100 \mathrm{NMP} / \mathrm{ml}$ antes, enquanto que após as medidas houve apenas 1 amostra com este microrganismo, com contagem bem inferior, de 1,5.10 NMP.mL $\mathrm{NL}^{-1}$ (a $1^{\text {a }}$ coleta) (Tabela 2).

Tabela 2 - Determinação de bactérias mesófilas, psicrotróficas e coliformes totais e termotolerantes, nas amostras de leite cru provenientes da propriedade 2, antes e após as sugestões de medidas profiláticas.

\begin{tabular}{|c|c|c|c|c|}
\hline & \multicolumn{4}{|c|}{ Mesófilos (UFC.mL ${ }^{-1}$ ) } \\
\hline & Coleta 1 & Coleta 2 & Coleta 3 & Coleta 4 \\
\hline ANTES & $2,2.10^{5}$ & $3,8.10^{4}$ & $1,0.10^{4}$ & $7,0.10^{3}$ \\
\hline DEPOIS & $9,3 \cdot 10^{2}$ & $1,6.10^{6}$ & 0 & $9,2 \cdot 10^{3}$ \\
\hline \multirow[t]{3}{*}{ Padrão (UFC/g) } & \multicolumn{4}{|c|}{$6,0.10^{5}$} \\
\hline & \multicolumn{4}{|c|}{ Psicrotróficos (UFC.mL $\left.\mathrm{mL}^{-1}\right)$} \\
\hline & Coleta 1 & Coleta 2 & Coleta 3 & Coleta 4 \\
\hline ANTES & 0 & 0 & 0 & $3,2.10^{2}$ \\
\hline DEPOIS & 0 & 0 & 0 & 0 \\
\hline \multirow[t]{3}{*}{ Padrão } & \multicolumn{4}{|c|}{ Não há } \\
\hline & \multicolumn{4}{|c|}{ Coliformes Totais (NMP.mL $\left.L^{-1}\right)$} \\
\hline & Coleta 1 & Coleta 2 & Coleta 3 & Coleta 4 \\
\hline ANTES & $>1100$ & $>1100$ & $4,6.10^{3}$ & $>1100$ \\
\hline DEPOIS & 0 & 0 & 0 & 0 \\
\hline \multirow[t]{3}{*}{ Padrão } & \multicolumn{4}{|c|}{ Não há } \\
\hline & \multicolumn{4}{|c|}{ Coliformes Termotolerantes (NMP.mL ${ }^{-1}$ ) } \\
\hline & Coleta 1 & Coleta 2 & Coleta 3 & Coleta 4 \\
\hline ANTES & 3,6 & $>1100$ & 0 & 0 \\
\hline DEPOIS & $1,5.10$ & 0 & 0 & 0 \\
\hline Padrão & & Não há & & \\
\hline
\end{tabular}

\section{Propriedade 3}

Na propriedade 3, em 3 das 4 coletas (2, 3 e 4) os valores encontrados para bactérias mesófilas após a sugestão das medidas profiláticas foram inferiores aos observados antes das medidas sugeridas, com diminuição mais expressiva na $2^{\text {a }}$ coleta, na qual o valor diminuiu de 6,1.10 3 UFC. $\mathrm{mL}^{-1}$ para a ausência deste grupo (Tabela 3). Nesta propriedade nenhuma amostra teve resultado acima do permitido pela legislação, com relação a mesófilos totais.

Para as bactérias psicrotróficas, não houve alteração, uma vez que nenhuma amostra estava contaminada por este grupo, em todas as coletas realizadas (Tabela 3). 
Para os coliformes totais e termotolerantes, verificou-se que houve melhoria nos índices, especialmente com relação ao primeiro grupo.

Para os coliformes totais, apenas 2 amostras coletadas após as sugestões de melhorias apresentaram este grupo, com valores baixos de contaminação (3,6 NMP.mL $\left.{ }^{-1}\right)$, enquanto que antes das medidas havia 4 amostras positivas, com elevadas contagens para este grupo, todos acima de $10^{3}$ NMP.mL $L^{-1}$ (Tabela 3).

Para os coliformes termotolerantes, havia 2 amostras com contagem para o grupo, uma acima de 1100 NMP.mL $\mathrm{mL}^{-1}$ antes, enquanto que após as medidas houve apenas 1 amostra com este grupo de micro-organismo, com este mesmo valor (Tabela 3).

Os resultados observados nesta propriedade demonstram que as medidas profiláticas sugeridas foram seguidas, obtendo melhorias nos índices de qualidade do leite.

Tabela 3 - Determinação de bactérias mesófilas, psicrotróficas e coliformes totais e termotolerantes, nas amostras de leite cru provenientes da propriedade 3, antes e após as sugestões de medidas profiláticas.

\begin{tabular}{|c|c|c|c|c|}
\hline & \multicolumn{4}{|c|}{ Mesófilos (UFC.mL $L^{-1}$ ) } \\
\hline & Coleta 1 & Coleta 2 & Coleta 3 & Coleta 4 \\
\hline ANTES & $5,4.10^{4}$ & $6,1 \cdot 10^{3}$ & $2,1.10^{3}$ & $8,1.10^{3}$ \\
\hline DEPOIS & $8,3.10^{4}$ & 0 & $5,9.10^{2}$ & $9,5.10^{2}$ \\
\hline \multirow[t]{3}{*}{ Padrão (UFC/g) } & \multicolumn{4}{|c|}{$6,0.10^{5}$} \\
\hline & \multicolumn{4}{|c|}{ Psicrotróficos (UFC.mL ${ }^{-1}$ ) } \\
\hline & Coleta 1 & Coleta 2 & Coleta 3 & Coleta 4 \\
\hline ANTES & 0 & 0 & 0 & 0 \\
\hline DEPOIS & 0 & 0 & 0 & 0 \\
\hline \multirow[t]{3}{*}{ Padrão } & \multicolumn{4}{|c|}{ Não há } \\
\hline & \multicolumn{4}{|c|}{ Coliformes Totais (NMP.mL $L^{-1}$ ) } \\
\hline & Coleta 1 & Coleta 2 & Coleta 3 & Coleta 4 \\
\hline ANTES & $>1100$ & $>1100$ & $4,6.10^{3}$ & $>1100$ \\
\hline DEPOIS & 3,6 & 0 & 3,6 & 0 \\
\hline \multirow[t]{3}{*}{ Padrão } & \multicolumn{4}{|c|}{ Não há } \\
\hline & \multicolumn{4}{|c|}{ Coliformes Termotolerantes (NMP.mL ${ }^{-1}$ ) } \\
\hline & Coleta 1 & Coleta 2 & Coleta 3 & Coleta 4 \\
\hline ANTES & 3,6 & $>1100$ & 0 & 0 \\
\hline DEPOIS & 0 & $>1100$ & 0 & 0 \\
\hline Padrão & & Não há & & \\
\hline
\end{tabular}

\section{Propriedade 4}

A propriedade 4 foi a que apresentou, de maneira geral, a melhor qualidade microbiológica do leite, dentre as propriedades avaliadas, especialmente após a adoção das medidas profiláticas de melhorias sugeridas.

Com relação às bactérias mesófilas totais, houve diminuição dos valores após as medidas, com exceção da $2^{\mathrm{a}}$ coleta, na qual houve aumento do índice, e da $3^{\mathrm{a}}$ coleta, na qual manteve-se 
ausência deste grupo de micro-organismos (Tabela 4). Assim como observado na propriedade 3, nenhuma amostra teve resultado acima do permitido pela legislação, com relação a mesófilos totais.

Para as bactérias psicrotróficas também houve melhoria, uma vez que nenhuma amostra estava contaminada por este grupo após as medidas, sendo que antes havia uma coleta positiva, com o valor de 4,1.10 $0^{5}$ UFC.mL $\mathrm{mL}^{-1}$ (Tabela 4).

Para os coliformes totais, uma amostra apresentou elevada contagem antes das medidas sugeridas (>1100 NMP.mL $\mathrm{mL}^{-1}$ ), sendo que após as medidas nenhuma apresentou este grupo.

Já para os coliformes termotolerantes, não houve alteração, uma vez que nenhuma amostra estava contaminada por este grupo, em todas as coletas realizadas, o que demonstra eficácia na adoção de medidas de higiene na propriedade (Tabela 4).

Diante dos resultados obtidos nesta propriedade, observou-se que o leite já tinha uma boa qualidade microbiológica em praticamente todas as coletas e, ainda assim, houve melhoria nos índices de qualidade após a adoção das medidas profiláticas sugeridas, indicando o empenho do produtor em melhorar a qualidade do leite produzido.

Tabela 4 - Determinação de bactérias mesófilas, psicrotróficas e coliformes totais e termotolerantes, nas amostras de leite cru provenientes da propriedade 4, antes e após as sugestões de medidas profiláticas.

\begin{tabular}{|c|c|c|c|c|}
\hline & \multicolumn{4}{|c|}{ Mesófilos (UFC.mL ${ }^{-1}$ ) } \\
\hline & Coleta 1 & Coleta 2 & Coleta 3 & Coleta 4 \\
\hline ANTES & $1,7.10^{3}$ & $1,1.10^{3}$ & 0 & $5,5.10^{2}$ \\
\hline DEPOIS & $1,8.10^{2}$ & $5,4.10^{3}$ & 0 & 0 \\
\hline \multirow[t]{3}{*}{ Padrão (UFC/g) } & & $6,0.10^{5}$ & & \\
\hline & \multicolumn{4}{|c|}{ Psicrotróficos (UFC.mL $\left.{ }^{-1}\right)$} \\
\hline & Coleta 1 & Coleta 2 & Coleta 3 & Coleta 4 \\
\hline ANTES & 0 & $4,1.10^{5}$ & 0 & 0 \\
\hline DEPOIS & 0 & 0 & 0 & 0 \\
\hline \multirow[t]{3}{*}{ Padrão } & \multicolumn{4}{|c|}{ Não há } \\
\hline & \multicolumn{4}{|c|}{ Coliformes Totais (NMP.mL $L^{-1}$ ) } \\
\hline & Coleta 1 & Coleta 2 & Coleta 3 & Coleta 4 \\
\hline ANTES & 0 & 0 & 0 & $>1100$ \\
\hline DEPOIS & 0 & 0 & 0 & 0 \\
\hline \multirow[t]{3}{*}{ Padrão } & \multicolumn{4}{|c|}{ Não há } \\
\hline & \multicolumn{4}{|c|}{ Coliformes Termotolerantes (NMP.mL ${ }^{-1}$ ) } \\
\hline & Coleta 1 & Coleta 2 & Coleta 3 & Coleta 4 \\
\hline ANTES & 0 & 0 & 0 & 0 \\
\hline DEPOIS & 0 & 0 & 0 & 0 \\
\hline Padrão & & Não há & & \\
\hline
\end{tabular}




\title{
4 Conclusão
}

Foi observado que após a aplicação das medidas profiláticas sugeridas houve uma melhoria na maioria dos indicadores microbiológicos das amostras de leite avaliadas nas propriedades. Concluiu-se que pequenas mudanças na maneira de manusear os animais, limpeza dos utensílios, refrigeração após a ordenha e higiene dos colaboradores, são fundamentais para obter um leite de melhor qualidade, sem que haja necessidade de muitos gastos e de diminuição dos lucros. Assim, com pequenas mudanças no manejo de produção, os produtores podem fornecer leite com melhor qualidade microbiológica.

\section{Agradecimentos}

Os autores agradecem a Universidade do Estado de Minas Gerais (UEMG, campus de Frutal) e a Fundação de Amparo à Pesquisa do Estado de Minas Gerais (FAPEMIG), pela Bolsa de Iniciação Científica concedida através do Programa de Apoio à Pesquisa (PAPq/UEMG/FAPEMIG).

\begin{abstract}
This study aimed to assess the microbiological quality of raw milk produced in four farms in Frutal IMG before and after the adoption of prophylactic measures in its attainment. The presence of mesophilic, psychrotrophic, total and fecal coliforms were determined. For quantification of mesophilic and psychrotrophic was made standard plate count with incubation at $35{ }^{\circ} \mathrm{C}$ for $48 \mathrm{~h}$. and $7{ }^{\circ} \mathrm{C}$ during 10 days, respectively. For determination of total coliforms, samples were inoculated into Brilliant Green Bile Broth $2 \%$, and incubated at $35{ }^{\circ} \mathrm{C}$ for up to $48 \mathrm{~h}$., and fecal coliform were inoculated in EC medium, and incubated at $45{ }^{\circ} \mathrm{C}$ for the same period. It was found that in property 1 there was a decrease of mesophilic bacteria in 75\% of samples. In property 2 this occurred in 50\% of samples. In these properties, in $25 \%$ of samples the result was above the limit established by law, after prophylactic measures. In the properties 3 and 4 was not detected presence above allowed. For psychrotrophic, was elevated count only in the 2nd collection of property 4, before the suggestion of prophylactic measures. For total coliforms, before the measures suggested, the properties 1, 2 and 3 had high level of contamination in all samples, while in the property 4 was a presence in only one. After prophylactic measures, it was observed that the contamination by this group decreased, with the exception of property 1. For fecal coliforms, in the properties 1 and 2 were reduced contamination after the prophylactic measures, while the property 3 remained index of 25\%. In the property 4 was not detected its presence in any sample. It was concluded that after the adoption of prophylactic measures there was an improvement in most indicators of microbiological milk samples evaluated.
\end{abstract}

Key-words: microbiological quality; raw milk; farms.

\section{Referências}

AMERICAN PUBLIC HEALTH ASSOCIATION (APHA). Committee on Microbiological Methods for Foods. Compendiun of Methods for the Microbiological Examination of Foods. Washington: APHA, 1992. 129p. 
ARCURI, E. F.; BRITO, M. A. V. P.; BRITO, J. R. F.; PINTO, S. M.; ÂNGELO, F. F.; SOUZA, G. N. Qualidade microbiológica do leite refrigerado nas fazendas. Arquivo Brasileiro de Medicina Veterinária e Zootecnia, v. 58 , n. 3, p. 440-446, 2006. http://dx.doi.org/10.1590/S0102-09352006000300024

BRASIL. Ministério da Agricultura. Departamento Nacional de Inspeção de Produtos de Origem Animal. Regulamento da Inspeção Industrial e Sanitária de Produtos de Origem Animal - R.I.I.S.P.O.A. Aprovado pelo decreto n. 30691 de 29 de junho de 1952. Alterado pelo Decreto 2244 de 04/06/1997. Brasília-DF. 1997.

BRASIL. Instrução Normativa n 62, de 29 de dezembro de 2011. Regulamenta a Produção, Identidade e Qualidade do Leite Tipo A, Técnico de Identidade e Qualidade de Leite Cru Refrigerado, Técnico de Identidade e Qualidade de Leite Pasteurizado e o Técnico da Coleta de Leite Cru Refrigerado e seu Transporte a Granel, em conformidade com os Anexos desta Instrução Normativa. Diário Oficial da União. Seção 1. 30/12/2011.

CHEN, L.; DANIEL, R. M.; COOLBEAR, T. Detection and impact of protease and lipase activities in milk and milk powders. International Dairy Journal, v. 13, p. 255-275, 2003.

FONSECA, L. F. L. Qualidade do leite e sua relação com equipamento de ordenha e sistema de resfriamento. In: Simpósio Internacional sobre Qualidade do Leite, 1., 1998, Curitiba, PR. Anais... Curitiba: [s.n.], 1998. p. 54-56.

GUERREIRO, P. K.; MACHADO, M. R. F.; BRAGA, G. C.; GASPARINO, E.; FRANZENER, A. S. M. Qualidade microbiológica de leite em função de técnicas profiláticas no manejo de produção. Ciência e Agrotecnologia, v. 29, n. 1, p. 216-222, 2005. http://dx.doi.org/10.1590/S1413-70542005000100027

PINTO, C. L. O.; MARTINS, M. L.; VANETTI, M. C. D.. Qualidade microbiológica do leite cru refrigerado e isolamento de bactérias psicrotróficas proteolíticas. Ciência e Tecnologia de Alimentos, Campinas, v. 26, n. 3, p. 645651, 2006. http://dx.doi.org/10.1590/S0101-20612006000300025

SANTOS, M. V.; FONSECA, L. F. L. Importância e efeito de bactérias psicrotróficas sobre a qualidade do leite. Revista Higiene Alimentar, São Paulo, v. 15, n. 82, p. 13-19, 2001.

SILVA, L. C. C.; BELOTI, V.; TAMANINI, R.; d'OVIDIO, L.; MATTOS, M. R.; ARRUDA, A M. C. T.; PIRES, E. M. F.. Rastreamento de fontes da contaminação microbiológica do leite cru durante a ordenha em propriedades leiteiras do Agreste Pernambucano. Semina: Ciências Agrárias, v. 32, n. 1, p. 267-276, 2011. http://dx.doi.org/10.5433/16790359.2011v32n1p267

SIQUEIRA, R. S. Manual de Microbiologia de Alimentos. Rio de Janeiro: Centro Nacional de Pesquisa de Tecnologia Agroindustrial de Alimentos - CTAA, Empresa Brasileira de Pesquisa Agropecuária - Embrapa, 1995.

Submetido em 13 mar. 2013; Aceito para publicação em 09 abr. 2014. 